OPEN ACCESS

Edited by:

Yongyi Yuan,

Department of Otolaryngology Head and Neck Surgery, PLA General

Hospital, China

Reviewed by:

Wenxue Tang,

Second Affiliated Hospital

of Zhengzhou University, China

Zhiqiang Yan,

Fudan University, China

*Correspondence:

Wenyan Li

wenyan_li2000@126.com

Huawei Li

hwli@shmu.edu.cn

†These authors have contributed equally to this work

Specialty section:

This article was submitted to

Molecular Medicine,

a section of the journal

Frontiers in Cell and Developmental

Biology

Received: 04 December 2020

Accepted: 21 January 2021

Published: 12 February 2021

Citation:

Wu M, Xia M, Li W and Li H (2021) Single-Cell Sequencing

Applications in the Inner Ear. Front. Cell Dev. Biol. 9:637779. doi: 10.3389/fcell.2021.637779

\section{Single-Cell Sequencing Applications in the Inner Ear}

\author{
Mingxuan $\mathrm{Wu}^{1 \dagger}$, Mingyu $\mathrm{Xia}^{1 \dagger}$, Wenyan $\mathrm{Li}^{1 *}$ and Huawei $\mathrm{Li}^{1,2,3,4 *}$ \\ 'ENT Institute and Department of Otorhinolaryngology, Eye and ENT Hospital, State Key Laboratory of Medical Neurobiology \\ and MOE Frontiers Center for Brain Science, Fudan University, Shanghai, China, ${ }^{2}$ Institutes of Biomedical Sciences, Fudan \\ University, Shanghai, China, ${ }^{3} \mathrm{NHC}$ Key Laboratory of Hearing Medicine, Fudan University, Shanghai, China, ${ }^{4}$ The Institutes \\ of Brain Science and The Collaborative Innovation Center for Brain Science, Fudan University, Shanghai, China
}

Genomics studies face specific challenges in the inner ear due to the multiple types and limited amounts of inner ear cells that are arranged in a very delicate structure. However, advances in single-cell sequencing (SCS) technology have made it possible to analyze gene expression variations across different cell types as well as within specific cell groups that were previously considered to be homogeneous. In this review, we summarize recent advances in inner ear research brought about by the use of SCS that have delineated tissue heterogeneity, identified unknown cell subtypes, discovered novel cell markers, and revealed dynamic signaling pathways during development. SCS opens up new avenues for inner ear research, and the potential of the technology is only beginning to be explored.

Keywords: single cell sequencing, hair cell, inner ear, supporting cell, spiral ganglion neuron

\section{INTRODUCTION}

The inner ear is one of the most intricate parts of the body, located within the petrous portion of the temporal bone with its attendant sensory structures responsible for auditory and balance function (Groves and Fekete, 2012). The cochlea is the auditory portion of the membranous labyrinth, while the vestibular organ collects motion, equilibrium, and spatial orientation information. Previous studies have defined some crucial signaling pathways - such as FGF, Notch, and Wnt - and genes such as Pax2 and Atoh1 - that play essential roles in the development and maintenance of the inner ear (Scheffer et al., 2015; Zhong et al., 2019). Each region of the sensory epithelium is composed of highly heterogeneous populations of cells depending on the physiological and anatomical criteria of that region (Szarama et al., 2012; Jeng et al., 2020; Ono et al., 2020; Yao et al., 2020), and this highlights the importance of examining the expression of a large number of genes at the single cell level.

Previous genetic studies have mainly focused on analyzing bulk tissue samples composed of millions of cells, and thus have only looked at the average expression of specific transcripts, which is dependent on the expression level of each gene as well as the populations of different cell subtype. Over the past centuries, major advances have been made in genomic studies, and single cell sequencing (SCS) has emerged as a powerful tool for studying the contributions from individual cells (Knouse et al., 2014; Cao et al., 2019; Pijuan-Sala et al., 2019). In this review, we will briefly show the developmental history and utilization of SCS technology in basic research, and we will summarize its utility in inner ear research that has improved our knowledge of inner ear cellular heterogeneity, inner ear development, genetic deafness, and hair cell (HC) regeneration. 


\section{THE DEVELOPMENT AND THE ADVANTAGES OF SCS TECHNOLOGY}

With the advent of next-generation sequencing, SCS technology has been developed and adopted to obtain genomic, transcriptomic, and epigenomic information from single cells (Tang X. et al., 2019). The data are collected following single cell isolation, capture, and lysis, nucleic acid extraction and amplification, and high-throughput sequencing, as shown in Figure 1A. Tang et al. (2009) modified the previously reported single-cell transcriptome amplification method and analyzed the transcriptomes of individual blastomeres, and this marked the beginning of single-cell omics. Later, Navin et al. (2011) flow-sorted nuclei and investigated copy number variations in liver tumor subpopulations. Further, Smart-Seq was developed as a robust method for improving read coverage and for enhancing the detailed analyses of alternative transcript isoforms and the identification of single-nucleotide polymorphisms (Ramskold et al., 2012).

The SCS procedures have been continuously updated and modified over the past decade. Advances in single-cell isolation have greatly expanded the fields of research, as cells of various tissue could be isolated and captured by different method. Magnetic-activated cell sorting (MACS), flow-activated cell sorting (FACS), and microfluidic platforms enable high throughput study, while laser capture microdissection (LCM) technology preserves original spatial information which may be of great importance under some circumstances. In addition, numerous methods have been developed for single cell genome, transcriptome, and epigenome study, as shown in Figure 1B. Coverage, sensitivity, efficiency as well as accuracy of these methods differ from each other because of distinct amplification process. Characteristics and suitable applications of different methods are summarized as shown in Tables 1-4.

Furthermore, researchers can now go beyond single-omics studies and can integrate multiple omics in a single cell. For example, the combination of DNA and RNA sequencing by DR-seq (DNA-mRNA sequencing) (Dey et al., 2015) or G\&Tseq (genome and transcriptome sequencing) (Macaulay et al., 2015) from the same cell can reveal genomic variations between individual cells, thus explaining changes at the transcription level. Techniques that analyze the epigenome and transcriptome of the same cell have been used to reveal the regulatory role of methylation and chromatin accessibility in gene expression (Angermueller et al., 2016; Hu et al., 2016; Clark et al., 2018), and Hou et al. (2016) have developed scTrio-seq (single-cell triple omics sequencing) that simultaneously obtains genome, DNA methylome, and transcriptome information from a single cell.

There has been an explosion of studies utilizing SCS in recent years due to its remarkable ability compared with traditional sequencing technology to detect new genes that might be missed by bulk sample sequencing and to discern previously unknown cell types (Proserpio and Lonnberg, 2016). In addition, SCS visualization of cell fate transition and possible cell origin has allowed the reconstruction of cell lineage trajectories of many important life activities in cells (Pijuan-Sala et al., 2019), and SCS has proven to be of great importance for illustrating new mechanism of tumorigenesis and metastasis and thus improving the diagnosis and treatment of cancer (Navin et al., 2011). In embryonic organ development, SCS provides genetic information at different stages, thus helping to identify master genes and regulatory signaling pathways in early embryonic development (Tang et al., 2010; Biase et al., 2014) and during the development of the cerebral cortex (Pollen et al., 2014), kidney (Wang P. et al., 2018), lung epithelium (Treutlein et al., 2014), etc. SCS has also promoted the identification of new species of microorganisms and clarified the molecular evolutionary mechanisms and kinetics of infection by obtaining genetic information at the single-cell level (McLean et al., 2013; Combe et al., 2015; Guo et al., 2017b). In studies of the immune system, where the cell subtypes are highly heterogeneous and are even more diversified after gene recombination, SCS has revealed single cell geneexpression networks in immune responses, therefore deepening our understanding of complex immune mechanisms and laying the foundation for advances in immunotherapy (Bossel BenMoshe et al., 2019; Rao et al., 2020). In reproduction and heredity studies, SCS is able to detect the dynamic genetic profiles of single germ cells (Hou et al., 2013; Chen et al., 2018; Wang M. et al., 2018) and embryonic cells (Wagner et al., 2018), which is significant for understanding germ cell genesis, alternative splicing patterns, and the key regulators of these processes. SCS also shows promise in reproductive disorders by improving prenatal and preimplantation genetic diagnosis (Li et al., 2017). SCS has also stimulated stem cell research, and embryonic stem cells and induced pluripotent stem cells have been traced by SCS to identify the regulators of embryonic and organ primordium outgrowth (Ealy et al., 2016). Various tissue-specific stem cells have also been explored with SCS, including hematopoietic stem cells (Kowalczyk et al., 2015), intestinal epithelium stem cells (Grun et al., 2015), lung epithelium stem cells (Ikonomou et al., 2020), neural stem cells (Llorens-Bobadilla et al., 2015), and germline stem cells (Guo F. et al., 2015). The single cell genetic patterns provide us with a more comprehensive means of evaluating the dynamic regulatory networks of progenitor cells in vivo, and this has helped to clarify the developmental process and has led to modifications of in vitro induction protocols. Broad applications of SCS in diverse fields of basic research are summarized in Figure 1C.

\section{SINGLE-CELL SEQUENCING IN INNER EAR CELL HETEROGENEITY}

Hair cells in the inner ear function in transducing the sound waves into electric signals (Hilding, 1953; Zwislocki, 1975; Balak et al., 1990); while SCs function in supporting the HCs and providing the potential pool for HC regeneration (Corwin and Cotanche, 1988; Balak et al., 1990). Damage from a variety of sources can impair $\mathrm{HC}$ function, including mutations in deafness genes, ototoxic drugs, aging, chronic cochlear infections, and noise overexposure (Wright, 1973; Cotanche et al., 1987; Hashino et al., 1991; Jiang et al., 2018). As shown in Figure 2, SCS enables the analysis of vast amounts of genetic data simultaneously at single-cell resolution with unbiased cell clustering, thus leading to 


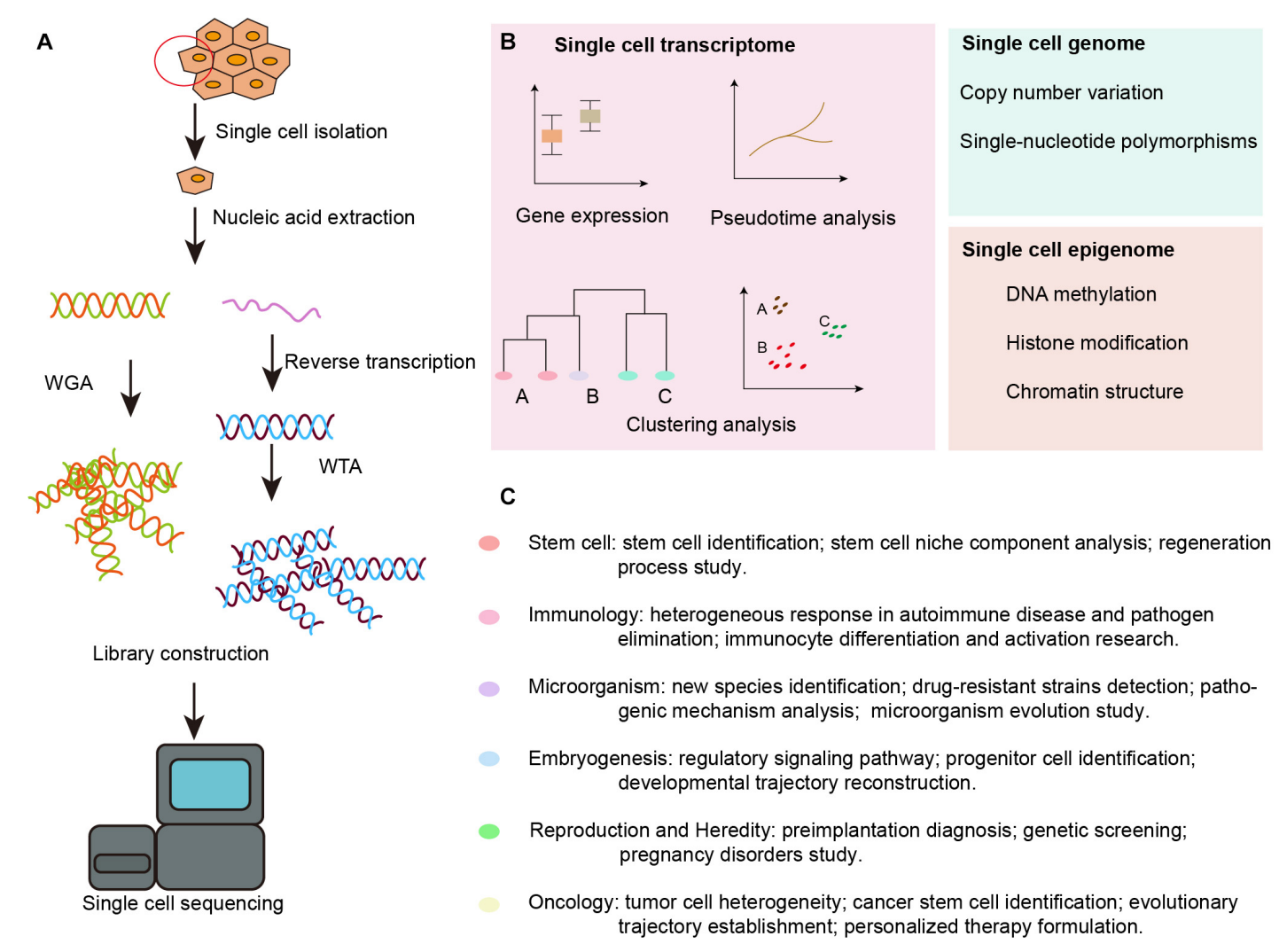

FIGURE 1 | Overview of SCS workflow and applications in the inner ear. (A) Schematic strategy of SCS workflow. After dissociation of the organ or tissue of interest to live single cell, cells are then captured by various methods and lysed to release RNA and DNA fragment, the former is reversed transcribed to synthesized cDNA. DNA fragment or CDNA must be amplified to generate sequencing library. Next-generation sequencing is subsequently performed to generate the readouts that can be assigned to single cells via cell-specific barcodes. (B) Analysis of single cell transcriptome, genome and epigenome data. (C) Diverse fields of basic research that have been impacted by SCS technologies. WGA, whole genome amplification; WTA, whole transcriptome amplification.

the identification of novel markers for inner ear resident cells and new cell subtypes of type II extrastriolar HCs, cochlear supporting cells (SCs), neuromast SCs, and spiral ganglion neurons (SGNs) (Burns et al., 2015; Shrestha et al., 2018).

\section{Heterogeneity of the Sensory Epithelium}

Based on single cell transcriptional profiles of postnatal day $(\mathrm{P}) 1$ mouse utricular epithelium, Burns et al. (2015) used known markers to identify three major groups [Gata2, Lmx1a, Slc26a4, and Cldn8 in transitional epithelial cells (TECs); Otog, Otoa, Jag1, Hes1, and Slc1a3 in SCs; Myo7a, Pou4f3, Otof, Calb2, and Ptprq in HCs] and subdivided them into seven subclusters following principal component analysis-based reduction. TECs contained one cluster, whereas SCs comprised two clusters and HCs consisted of four clusters. In unbiased trajectory analysis, HC.i appeared to be in a transitional state between SC.ii and HC.iiiiv, which is consistent with a study confirming the development of HCs from SCs (Wang et al., 2015). Surprisingly, HC.ii was assigned between TECs and HC.iii-iv, which suggested novel TEC-like progenitor cells located outside the sensory epithelium. In addition, striolar HCs and SCs seem to be distinct cell subtypes compared with their counterparts in the extrastriolar region (Wang et al., 2015; Li et al., 2016). Striolar HCs express high levels of oncomodulin and clusterin, while striolar SCs distinctly express the otolithic membrane glycoprotein betatectorin, the transcription factor Gata3, and the retinoic acidinactivating protein Cyp26b1. In addition, P1 striolar SCs have a greater propensity to regenerate into HCs in response to Notch inhibition. Together, these results indicate that the striola is a molecularly distinct region within the utricle. Another study analyzed single utricular HC data from P1, P12, and P100 mice and identified Spp1 as a specific marker for Type I HCs and Mapt and Anxa4 as markers for Type II HCs (McInturff et al., 2018). In addition, Ellwanger et al. (2018) identified two classes of type II extrastriolar HCs based on the discrepant expression of ATP2B2, CCDC50, MYO1H, TMC2, and TNNC2 (Ellwanger et al., 2018).

Burns et al. (2015) adopted a similar process to analyze the single cell transcriptomes of P1 cochlear epithelium tissue and identified four major clusters of cells - HCs, SCs, medial non-sensory cells (NSC.i) and lateral non-sensory cells (NSC.ii). Rasd2, Anxa4, and Pcp4 were found to be novel markers for HCs, and Cdh4 and Mial were identified as medial SC markers and Cntn1 as a lateral SC marker. Although genetic heterogeneity within the clusters indicated possible cell subtypes, definitive conclusion was not available in Burns's study because of the limited sample size, and this highlights the importance of the 
TABLE 1 | Comparison of single-cell isolation methods.

\begin{tabular}{|c|c|c|c|}
\hline Item & Advantage & Disadvantage & References \\
\hline Serial dilution & $\begin{array}{l}\text { Simple operation, } \\
\text { low cost }\end{array}$ & $\begin{array}{l}\text { Low throughput, } \\
\text { cell loss, difficulty in } \\
\text { filtering target cells }\end{array}$ & $\begin{array}{l}\text { Gross et al., } \\
2015\end{array}$ \\
\hline Manual pipetting & $\begin{array}{l}\text { Simple operation, } \\
\text { low cost }\end{array}$ & Low throughput & $\begin{array}{l}\text { Gross et al., } \\
2015\end{array}$ \\
\hline $\begin{array}{l}\text { Robotic } \\
\text { micromanipulation }\end{array}$ & Precise separation & $\begin{array}{l}\text { Low efficiency, } \\
\text { dependence on } \\
\text { apparatus, } \\
\text { mechanical } \\
\text { damage }\end{array}$ & $\begin{array}{l}\text { Guo et al., } \\
2017 a\end{array}$ \\
\hline MACS & $\begin{array}{l}\text { High throughput, } \\
\text { high accuracy }\end{array}$ & $\begin{array}{l}\text { Mechanical } \\
\text { damage, } \\
\text { requirement for } \\
\text { high cell } \\
\text { abundance }\end{array}$ & $\begin{array}{l}\text { Guo and } \\
\text { Cairns, } 2019\end{array}$ \\
\hline FACS & $\begin{array}{l}\text { High throughput, } \\
\text { high accuracy }\end{array}$ & $\begin{array}{l}\text { Mechanical } \\
\text { damage, } \\
\text { requirement for } \\
\text { high cell } \\
\text { abundance and } \\
\text { fluorescence } \\
\text { intensity }\end{array}$ & $\begin{array}{l}\text { Shapiro et al. } \\
2013\end{array}$ \\
\hline LCM & $\begin{array}{l}\text { High accuracy, } \\
\text { conservation of } \\
\text { spatial information }\end{array}$ & $\begin{array}{l}\text { Low efficiency, high } \\
\text { cost, likely } \\
\text { contamination form } \\
\text { adjacent cells }\end{array}$ & $\begin{array}{l}\text { Nichterwitz } \\
\text { et al., } 2016\end{array}$ \\
\hline $\begin{array}{l}\text { Microfluidic } \\
\text { platforms }\end{array}$ & $\begin{array}{l}\text { High throughput, } \\
\text { high accuracy, } \\
\text { available } \\
\text { commercial } \\
\text { platform }\end{array}$ & $\begin{array}{l}\text { Dependence on } \\
\text { homogeneous cell } \\
\text { size }\end{array}$ & $\begin{array}{l}\text { Macosko } \\
\text { et al., } 2015\end{array}$ \\
\hline
\end{tabular}

MACS, magnetic-activated cell sorting; FACS, flow-activated cell sorting; LCM, laser capture microdissection.

TABLE 2 | Comparison of single-cell DNA sequencing technologies.

\begin{tabular}{|c|c|c|c|c|}
\hline Item & Coverage & Characteristics & Application & References \\
\hline DOP-PCR & Low & $\begin{array}{l}\text { Exponential amplification, } \\
\text { simple operation, fast } \\
\text { speed, } \\
\text { sequence-dependent bias, } \\
\text { high allele dropout rate }\end{array}$ & $\mathrm{CNV}$ & $\begin{array}{l}\text { Arneson } \\
\text { et al., 2008; } \\
\text { Huang } \\
\text { et al., } 2015\end{array}$ \\
\hline MDA & Medium & $\begin{array}{l}\text { Exponential amplification, } \\
\text { high replication fidelity, } \\
\text { sequence-dependent bias, } \\
\text { normalization ineffective }\end{array}$ & SNV & $\begin{array}{l}\text { Spits et al., } \\
2006\end{array}$ \\
\hline MALBAC & High & $\begin{array}{l}\text { Linear amplification, high } \\
\text { accuracy for CNV } \\
\text { detection, low false } \\
\text { negative rate for SNV } \\
\text { detection }\end{array}$ & $\begin{array}{l}\text { CNV and } \\
\text { SNV }\end{array}$ & $\begin{array}{l}\text { Zong et al., } \\
2012\end{array}$ \\
\hline
\end{tabular}

DOP-PCR, degenerate oligonucleotide-primed polymerase chain reaction; MDA, multiple displacement amplification; MALBAC, multiple annealing and looping-based amplification cycles; CNV, copy number variation; SNV, singlenucleotide polymorphisms.

power of sequencing (Burns et al., 2015; McInturff et al., 2018). Hoa et al. (2020) collected single cell transcriptomes of cochlear SCs and categorized adult cochlear SCs into two subclusters
TABLE 3 | Comparison of single-cell RNA sequencing technologies.

\begin{tabular}{|c|c|c|c|}
\hline Item & Coverage & Characteristics & References \\
\hline Smart-seq/seq2 & Full length & High sensitivity, low efficiency & $\begin{array}{l}\text { Ramskold } \\
\text { et al., 2012; } \\
\text { Picelli et al., } \\
2014\end{array}$ \\
\hline Quarz-seq/seq2 & Full length & $\begin{array}{l}\text { High sensitivity, high } \\
\text { reproducibility }\end{array}$ & $\begin{array}{l}\text { Sasagawa } \\
\text { et al., 2013, } \\
2018\end{array}$ \\
\hline CEL- seq/seq2 & Full length & $\begin{array}{l}\text { High accuracy, } \\
\text { sequence-dependent bias }\end{array}$ & $\begin{array}{l}\text { Hashimshony } \\
\text { et al., } 2012 \text {, } \\
2016\end{array}$ \\
\hline Drop-seq & $3^{\prime}$-end & $\begin{array}{l}\text { High efficiency, low cost, } \\
\text { highly parallel analysis }\end{array}$ & $\begin{array}{l}\text { Macosko et al., } \\
2015\end{array}$ \\
\hline inDROP-seq & $3^{\prime}$-end & $\begin{array}{l}\text { High throughput, low } \\
\text { efficiency }\end{array}$ & $\begin{array}{l}\text { Klein et al., } \\
2015\end{array}$ \\
\hline STRT-seq & 5 '-end & $\begin{array}{l}\text { High accuracy, } \\
\text { sequence-dependent bias }\end{array}$ & $\begin{array}{l}\text { Islam et al., } \\
2012\end{array}$ \\
\hline MARS-seq & $3^{\prime}$-end & High sensitivity, high accuracy & $\begin{array}{l}\text { Jaitin et al., } \\
2014\end{array}$ \\
\hline Cyto-seq & $3^{\prime}$-end & $\begin{array}{l}\text { Direct analysis of complex } \\
\text { samples, relatively expensive } \\
\text { and time-consuming }\end{array}$ & Fan et al., 2015 \\
\hline
\end{tabular}

TABLE 4 | Comparison of single-cell epigenome technologies.

\begin{tabular}{|c|c|c|c|}
\hline Item & Application & Characteristics & References \\
\hline scRRBS-seq & DNA methylation & $\begin{array}{l}\text { Low throughput, low } \\
\text { coverage rate }\end{array}$ & $\begin{array}{l}\text { Guo H. et al., } \\
2015\end{array}$ \\
\hline scBS-seq & DNA methylation & $\begin{array}{l}\text { Low throughput, low } \\
\text { coverage rate }\end{array}$ & $\begin{array}{l}\text { Smallwood } \\
\text { et al., } 2014\end{array}$ \\
\hline scCGl-seq & DNA methylation & $\begin{array}{l}\text { Low throughput, high } \\
\text { coverage rate }\end{array}$ & Han et al., 2017 \\
\hline scChlL-seq & Histone modification & $\begin{array}{l}\text { Low throughput, high } \\
\text { coverage rate }\end{array}$ & $\begin{array}{l}\text { Harada et al., } \\
2019\end{array}$ \\
\hline scCUT\&tag & Histone modification & $\begin{array}{l}\text { High throughput, low } \\
\text { coverage rate }\end{array}$ & $\begin{array}{l}\text { Kaya-Okur et al., } \\
2019\end{array}$ \\
\hline scChlC-seq & Histone modification & $\begin{array}{l}\text { Low throughput, low } \\
\text { coverage rate }\end{array}$ & Ku et al., 2019 \\
\hline scATAC-seq & Chromatin structure & $\begin{array}{l}\text { High throughput, high } \\
\text { coverage rate }\end{array}$ & $\begin{array}{l}\text { Buenrostro } \\
\text { et al., } 2015\end{array}$ \\
\hline
\end{tabular}

that differentially expressed S100a6, Pla2g7, Tuba1b, and Spry2. S100a6 and Pla2g7 were identified as medial SC markers, and Tuba $1 b$ and Spry 2 were identified as lateral SC markers.

Comparisons of gene expression between inner HCs (IHCs) and outer $\mathrm{HCs}$ (OHCs) provide a deeper understanding of these cells' unique functions. Using AUC rankings, $\mathrm{Ocm}$ and Sri were identified as the top two most upregulated genes in OHCs, both of which are associated with calcium regulation (Ranum et al., 2019). Expressed predominantly by OHCs, Ocm encodes Oncomodulin, a calcium-buffering protein that is essential for mechanoelectric transduction and electromotility amplification (Simmons et al., 2010). Sri encodes sorcin, a regulator of calciumbased excitation-contraction (Fowler et al., 2008). OHCs express $\mathrm{Ca} 2+$ release channels/ryanodine receptors in a pattern similar to cardiac myocytes, which raises the possibility that $\mathrm{Ca} 2+$ plays a similar role in regulating OHC motility (Grant et al., 2006). The 


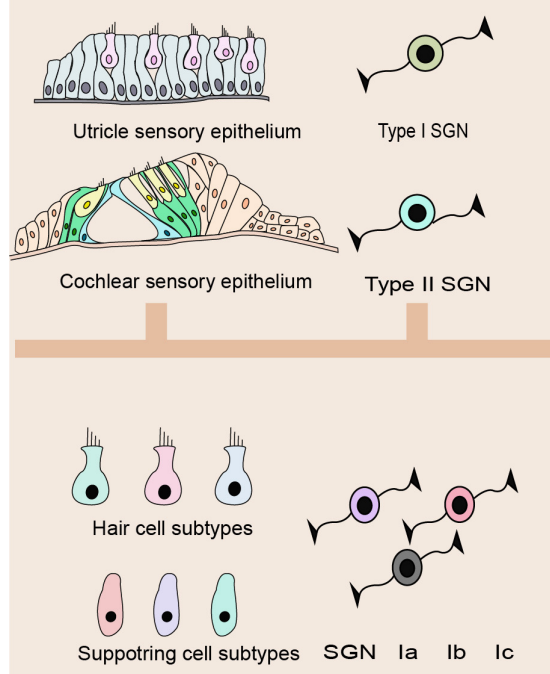

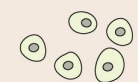

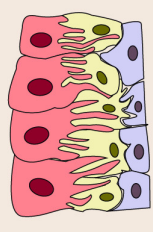

Stria Vascularis

Otocyst and neuroblast

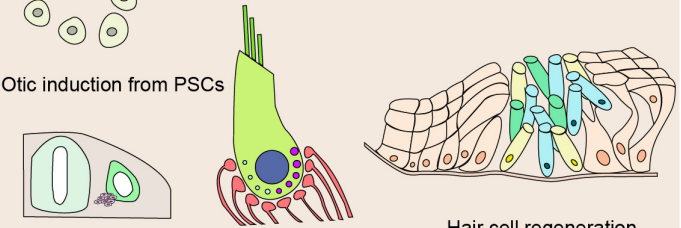

Hair cell regeneration
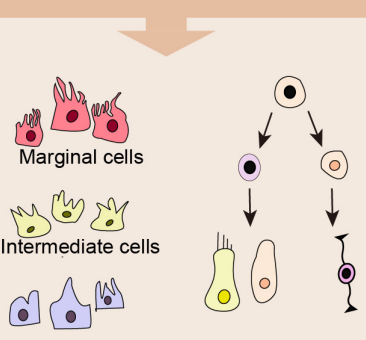

Inner ear lineage development

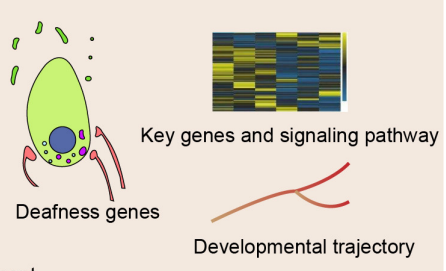

FIGURE 2 | Applications of SCS in basic research. Applications of single cell sequencing (SCS) in the inner ear enable recognition of previously unknown cell subtype and novel marker genes of hair cells (HCs), supporting cells (SCs), spiral ganglion neurons (SGNs), and cells in the stria vascularis (SV), identification of unappreciated exons and splicing diversity of genetic deafness and reconstruction of developmental trajectory and regeneration process.

expression of other components required for calcium-mediated excitation-contraction in the $\mathrm{OHC}$ transcriptome is consistent with this hypothesis and suggests a unique requirement for the tight regulation of calcium in these cells (Ranum et al., 2019).

Compared with mammals, non-mammalian vertebrates constantly regenerate sensory HCs in lateral line organs in order to replace senescent or injured cells, and this occurs through SC proliferation and differentiation (Steiner et al., 2014; Romero-Carvajal et al., 2015; Chen et al., 2017; Zhang et al., 2018, 2019). Regular RNA-Seq has been extensively used in analyzing the proliferation and differentiation ability of SCs (Waqas et al., 2016a; Cheng et al., 2017; Zhang et al., 2017; You et al., 2018), and scRNA-seq was used to identify quiescent and activated stem cell populations and their spatial arrangements in zebrafish neuromasts (Lush et al., 2019). The SC subtypes included central SCs (Lfng, Ebf3a, Gata2a/b, and Slc1a3a/Glasta), anterior-posterior (A/P) SCs (Cx44.2, Fap, Fgf10a, and $H m \times 2)$, dorsal-ventral (D/V) amplifying SCs (Sost, Fsta, Srrt/Ars, Six2b, and Adcyap1b), and dividing/differentiating SCs (Dld, Her4.1, Pcna, and Atoh1b). Dividing/differentiating SCs were considered to be an $\mathrm{HC}$ progenitors cluster in the HC lineage with young HCs and mature HCs, which were marked by Atoh $1 b$ and Tekt3, respectively. Mantle cells had enriched expression of Cldne, Crb3b, Crip1, and Cts12. The authors then mapped the amplifying divisions to $\mathrm{D} / \mathrm{V}$ poles and the differentiating divisions to the center and thus identified distinct locations of two SC lineages, while cells in the A/P poles were relatively quiescent. Along this timeline, cells lose their expression of SC and stem cell genes and take on HC-specific markers. Genes related to translation, cell cycle regulation, and Notch signaling (Dla, Dlb, Dlc, Dld) were downregulated, suggesting their roles in early developmental stages rather than subsequent differentiation stages.

\section{Heterogeneity of Cochlear SGNs}

After mechanical stimulation of auditory HCs, sound information is conveyed to the dendrites of SGNs via synaptic vesicles containing the neurotransmitter glutamate (Eybalin et al., 1996; Yan et al., 2018; Guo et al., 2019; Liu et al., 2019). The perception of auditory information - including sound frequency, intensity, timbre, and pitch - is a complex process that appears to be associated with SGN diversity (Pfeiffer and Kiang, 1965; Sachs et al., 1974; Liberman, 1982; Temchin, 1988). Based on recent studies of SGN single-cell transcriptomes, three novel subclasses of type I neurons have been identified (Petitpre et al., 2018; Shrestha et al., 2018; Sun et al., 2018). The clustering of type I SGN subtypes in the three studies used almost identical gene sets and obtained similar transcriptional profiles, but the authors named the three subtypes differently. Genes were found to enriched in each subtype, including CALB2, Trim54, Rxrg in type Ia neurons; CALB1, Runx1, and Ttn in type Ib neurons; and Pou4f1, Lypd1, Grm8, Kcnc2, Lypd1, and Runx1 in type Ic neurons (Petitpre et al., 2018; Shrestha et al., 2018; Sun et al., 2018). Shrestha et al. (2018) examined genes involved in synaptic transmission and electrophysiological properties. The expression of AMPA-type glutamate receptor subunit Grik4, metabotropic receptor subunit Grm8, and dopamine receptor subunit Drd1 were highly increased in Ic SGNs, and the cholinergic receptor subunits Chrnal and Chrna4 were enriched in Ia SGNs. As for the genes encoding $\mathrm{K}^{+}$channel subunits, Kcnq4 was detected in Ia SGNs, while Kcnd2 and Kcnip2 were expressed in Ib SGNs and Kcnj9 was expressed in Ic SGNs. Cacnalb, Cacnalh, and 
Cacna2d1 are voltage-gated $\mathrm{Ca}^{2+}$ channels that were enriched in Ia SGNs. The leaky sodium channel Nalcn was detected tin Ib and Ic SGNs, and the voltage-gated sodium channel subunit $\operatorname{Scn} 2 b$ was expressed in an increasing gradient from Ia to Ic SGNs. Based on a previous study that SGNs projecting to different positions along the basolateral surface of IHCs differ in spontaneous firing rate (SR) (Liberman, 1982), Shrestha assumed that type Ia SGNs that projected onto the pillar side of the IHC and formed synapses with small ribbons corresponded to high-SR fibers, that Ib SGNs on the middle of the basolateral surface with medium ribbons corresponded to medium-SR fibers, and that Ic SGNs that projected onto the modiolar side with small ribbons corresponded to low-SR fibers (Shrestha et al., 2018). In addition, enriched gene sets for mitochondrial function and neurofilament formation in type Ia SGNs were consistent with increased mitochondrial content and fiber thickness in high-SR neurons (Sun et al., 2018). They also found tonotopic differences in functionally relevant genes within these subpopulations. Efna1, for example, was condensed in the middle and base compared with the apex within Ib SGNs and was enriched in Ia and Ic SGNs at the base (Shrestha et al., 2018). The transcriptional profiles and anatomical arrangements, combined with their electrophysiological properties, suggested that the heterogeneous neural populations were involved in encoding of sound intensities and for maintaining of hearing discrimination in noisy environments (Petitpre et al., 2018). This diversity of cochlear neurons is established at birth, followed by refinement over the first postnatal week that requires intact HC mechanotransduction activity (Shrestha et al., 2018; Sun et al., 2018).

\section{Heterogeneity of the Stria Vascularis}

Hair cell mechanotransduction requires high- $\mathrm{K}^{+}$endolymph and positive endocochlear potential (EP), both of which are generated by the stria vascularis (SV), a non-sensory epithelial tissue located on the lateral side of the cochlear duct (Wangemann, 2002; Patuzzi, 2011). Marginal cells (MCs), intermediate cells (ICs), and basal cells (BCs) have been identified in the $\mathrm{SV}$ and are indispensable for endolymph ionic homeostasis and EP maintenance.

Korrapati et al. (2019) performed single cell RNA-seq and single nucleus RNA-seq to investigate SV cell populations. Known markers, including Kcne1 and Kcnq1 for MCs, Cd44 and Met for ICs, Cldn11 and Tjp1 for BCs, and Slc26a4 for spindle/root cells, were used to define cell identities after unbiased clustering. Gene ontology (GO) analysis showed that MCs had enriched expression of genes involved in positive regulation of $\mathrm{K}^{+}$transport, $\mathrm{Ca}^{2+}$-transporting ATPase activity, and G-protein-coupled receptor complex formation, that ICs exhibited high expression of $\mathrm{H}^{+}$-transporting ATPase activity, neutrophil degranulation, and interleukin-28 receptor complex formation, and that BCs expressed genes involved in rhodopsin expression regulation and platelet alpha granule lumen. The transcriptional profiles of the SV cell populations suggested roles for MCs and ICs in ion homeostasis maintenance and possible interactions between SV cells (ICs and BCs) and the immune system. In addition, novel markers, including Abcgl and Heyl in MCs, Nrp2 and Kcnj13 in ICs, Sox 8 and Nr2f2 in BCs, and P $2 r x 2$ and Kcnj16 in spindle/root cells were discovered and confirmed by smFISH (single molecule fluorescence in situ hybridization).

\section{SINGLE-CELL SEQUENCING IN INNER EAR DEVELOPMENT}

Generation of the entire otic lineage from non-neural ectoderm (NNE) through pre- placodal ectoderm (PPE) and the posterior placode fates remains elusive, but in vitro studies have contributed to understanding the molecular mechanism of early otic lineage formation. Ealy et al. (2016) used human embryonic stem cells and induced pluripotent stem cells to test conditions for stepwise induction of NNE to the otic lineage, and the process was monitored by SCS. They successfully developed a protocol that combined BMP, Wnt, and FGF signaling regulations with retinoic acid treatment to generate a lineage that chronologically expressed markers of NNE (Dlx3, Dlx5, Dlx6, Tfap2a, Tfap $2 c$, Gata3, and Gata2), PPE (Eya1, Eya2, Six1, and Six4), and ultimately of the otic lineage (Myosin7a, Foxi3, Fbxo2, Pax2, and Pax8). This breakthrough showed the potential of applying SCS in the refinement of the cell guidance protocol.

The otocyst is regarded as the origin for almost all cells of the inner ear, including sensory epithelial cells and neurons. Durruthy-Durruthy et al. (2014) conducted scRNA-seq of cells from mouse otocysts and neuroblasts at embryonic day (E)10.5, which is the developmental stage at which delaminating and migrating neuroblast cells coexist. Clusters identified by known markers included early neuroblasts (by Neurog1 and Fgf3), postdelaminated neuroblasts (by Isl1, Neurod1, and Eya1), ventral otocysts (by Lfng, Sox2, Pax2, and Gli1), and dorsal otocysts (by Bmp4, Dlx5, Gata2, and Oc90). Because neuroblasts are committed to their lineage, repressed Shh and Wnt signaling was observed, as shown by downregulation of Shh pathway genes (Smo and Ptc2 and Gli3) and Wnt pathway genes (Fzd2, Fzd7, $F z d 8$, and Axin2). Fgf signaling was also downregulated and Fgf gene ( $F g f 8$ and $F g f 10$ ) and Fgfr1 expression was decreased and Fgfr1 antagonist Spry2 expression was increased along the axis of development. However, Notch signaling showed a bimodal distribution, and expression of Dll1, Jag1, Notch2, Hes1, Hes5, and Hey2 declined while expression of Jag2 and Hey 1 increased toward the later stages. In addition, two distinct cell populations were identified within the late neuroblasts that expressed Foxg1 and Jag2 asymmetrically, which implied the separation of cochlear and vestibular ganglion neurons ( $\mathrm{Lu}$ et al., 2011; He et al., 2019, 2020). In the otocysts, Notch signaling was mapped to the dorso-anterior side (Notch2) and ventro-anterior side (Hes1, Hey1, and Hey2), and the Shh receptor gene Ptc2 and effector gene Gli3 were expressed in cells located in the ventral part of otocysts. A small group of cells in the ventral otocyst cell cluster were identified as potential prosensory predecessors due to their enriched expression of prosensory markers (Sox2, Jag1, and Lfng) and weak expression of the early neuroblast marker Neurog1. Signaling pathway analysis of this subcluster revealed active Notch (Hey1, 
Hey2, Hes1, Hes5, Dll1, Jag1, and Notch2) and Shh signaling (Gli2, Gli3, and Smo) activity and autonomously regulated Fgf signaling (Fgf3, Fgf10, Spry1, and Spry2), indicating the complexity of the signals that need to be integrated to induce the prosensory lineage. Fbxo2 and Otol1 were otic-specific candidate genes in the heterogeneous area that gives rise to the prosensory domains.

The endolymphatic sac forms at E10 and is the earliest structure to arise from the otocyst, and it is important in fluid resorption during inner ear development (Morsli et al., 1998; Raft et al., 2014). The major cell types in the endolymphatic sac are ribosome-rich cells (RRCs) and mitochondria-rich cells (MRCs) (Dahlmann and von During, 1995). Honda et al. (2017) conducted single-cell RNA-seq of the mouse endolymphatic sac from E12.5 to P30. Early RRCs predominantly expressed genes involved in proteins secretion (Dmkn, Clu, Igsf1, and Cyr61), while mature RRCs expressed genes related to innate immunity (Lcn2, Slpi, and Serping1). In contrast, MRCs expressed high levels of genes related to ion transport (Slc26a4, Atp6v1b1, Clcnkb, Slc4a9, Kcnma1, and Slc34a2). These results confirmed that embryonic endolymphatic sac fluid resorption is carried out by MRCs and is dependent on the anion exchanger SLC26A4.

After cell fate commitment, primitive cells undergo a series of changes in gene expression and cellular morphology to become mature cells. McInturff et al. (2018) identified new markers for utricular HCs (Spp1 for Type I HCs and Mapt and Anxa4 for Type II HCs), and they traced these genes to study the temporal and spatial development of utricular HCs. They found that type I HCs develop from the posterior-medial side to the anteriorlateral side and that type II HCs initially develop in the striolar region and extend to the periphery. Marked by Spp1, 90\% of type I HCs arise between E11.5 and E14.5, while almost all type II HCs develop postnatally.

In HCs, hair bundle assembly and protrusion are prerequisites for their mechanotransduction function (Ó Maoiléidigh and Ricci, 2019). Although four stages of developing bundles have been defined according to their structural pattern as pregrowth, initial growth, widening, and secondary growth (Tilney et al., 1992), the molecular basis for this division has remained poorly understood. Using SCS, Zhu et al. (2019) found that utricle hair bundle assembly and growth requires regulation of local $\mathrm{Ca}^{2+}$ concentrations. The $\mathrm{Ca}^{2+}$ regulator Calb2 and the calcium pump Atp2b2 were shown to be important for stereocilia growth because the highest level of Calb2 protein occurred at the onset of the secondary growth and Aatatp2b2 protein expression peaked during stereocilia widening (Ellwanger et al., 2018). It has been confirmed that HCs use existing monomeric actin to build hair bundles without significant upregulation of actin gene transcription (Tilney and Tilney, 1988). Zhu et al. (2019) reported the use of single-cell proteomics analysis combined with single-cell RNA-seq to study the utricles of E15 chickens. The authors found previously unannotated proteins that were abundant in different populations, such as GSTO1, GPX2, CRABP1, and AK1 in HCs and TMSB4X and AGR3 in SCs. Single cell proteomics revealed that the actin monomer binding protein thymosin b4 (TMSB4X) was abundant in SCs and that its expression decreased as progenitor cells developed into HCs. Comparative single-cell RNA-seq analysis showed that Tms $b 4 x$ transcripts were downregulated when transcription of Atoh1 was activated, which suggested that existing monomeric actin is made available for hair bundle assembly through the degradation of $T m s b 4 x$.

\section{SINGLE-CELL SEQUENCING IN DEAFNESS}

Numerous variants in genes related to deafness have been identified, thus illustrating the heterogeneous genetic background of deafness (Shearer et al., 2014). Ranum et al. (2019) used single cell full-length reverse transcriptional analysis with long-read sequencing to identify novel exons and to reveal the unappreciated splicing diversity among deafness-associated genes. They analyzed 12 deafness-associated genes and detected 20 unannotated exons, including exon $1 \mathrm{~B}$ of Cabp2 and exons $1 \mathrm{~B}, 22 \mathrm{~B}, 9 \mathrm{~B}$, and $31 \mathrm{~B}$ of Cacnald. Their work showed that the heterogeneity and complexity of genetic deafness is greater than previously believed and suggested that current genetic tests for deafness are incomplete.

Single-cell sequencing technology can also be used to demonstrate the mechanism by which genetic changes lead to specific phenotypes. For example, chromodomain helicase DNA binding protein 7 (Chd7) has been shown to be involved in early inner ear development (E8.5-E10.5) by regulating ATP-dependent nucleosome remodeling (Adams et al., 2007; Bouazoune and Kingston, 2012), and single cell transcriptomes of E10.5 mouse otocysts showed that loss of Chd7 leads to the misexpression of neurogenic genes (Neurog1 and Neurod1), the ventral-associated gene Lfng, and Notch genes (Heyl and Hey2) in dorsal otic cells (Durruthy-Durruthy et al., 2018). This indicated that Chd7 mutant dorsal otic cells aberrantly adopt mixed dorsal and neurogenic fates, probably because of additional Notch signals. Type II transmembrane serine protease (Tmprss3) is another gene that is required for normal hearing, and mutations in Tmprss 3 cause rapid cochlear HC loss between P12 and P14 (Fasquelle et al., 2011). Single cell RNA-seq of inner ear organoid cells revealed elevated expression of apoptosis genes and genes associated with the extracellular matrix in Tmprss3-knockout hair cells, while Kcnma1 (which encodes the $\alpha$ subunits of a $\mathrm{Ca} 2+$-activated $\mathrm{K}+$ channel), Ca2+-binding protein genes (Myl1, Pvalb, Cib2, Mylpf, and Tnnc2), and the Ca2+regulator gene $\operatorname{Sln}$ were downregulated, suggesting the important role for Tmprss 3 in cellular homeostasis (Tang P. C. et al., 2019).

\section{SINGLE-CELL SEQUENCING IN HC REGENERATION}

In mammals, the loss of cochlear HCs leads to permanent hearing impairment because these cells only exhibit very limited spontaneous regeneration capacity and only within the first postnatal week, and such regeneration occurs via the mitotic 
proliferation or transdifferentiation of SCs (Ni et al., 2016; Waqas et al., 2016b; Wu et al., 2016; He et al., 2017; McGovern et al., 2019). Researchers have focused on the genes involved in cell cycle progression in adult cochlear SC transcriptional profiles generated by SCS and found that lateral SCs (pillar and Deiters' cells) express some of the transcripts that are enriched in Lgr5 + neonatal SCs, including Cdkn1b, Cks1b, Mcm3, $M d m 2$, and $S h c 3$, while genes involved in G1/S transition are more preferentially expressed in adult cochlear SCs (Hoa et al., 2020). GO molecular function and cellular component analysis indicated that the inability of adult cochlear SCs to reenter the cell cycle was related to cyclin-dependent protein serine/threonine kinase activity and condensed chromatin at the centromere.

Overexpression of Atoh1 can induce SCs to differentiate into ectopic HCs (Zheng and Gao, 2000; Gubbels et al., 2008; Lewis et al., 2012). In work by Yamashita et al. (2018), the Atoh1-overexpression transgene was driven by Fgfr3 (in Deiters' cells and Pillar cells) in mouse cochleae after tamoxifenmediated induction at P12, and single-cell transcriptomes were obtained at P12, P26, and P33. Atoh1-induced HCs were divided into three groups based on their developmental stages, from initial HCs cells to mature HCs. Along the regeneration trajectory, the expression of HC markers (Myo6, Rasd2, Chrna9, Pvalb, Pou4f3, and Chrna10) increased. Atoh1 and Pou 43 were considered to be key reprogramming factors, while other transcription factors, including Barhl1 and Lhx3, improved the conversion efficiency. In addition, the authors found that Isl1 boosted the efficiency Atoh1-mediated SC to $\mathrm{HC}$ conversion.

The Notch and Wnt pathways and their interactions were investigated in $\mathrm{HC}$ regeneration, and it was shown that Notch signaling downregulation after $\mathrm{HC}$ ablation led to the disinhibition of Wnt signaling and the induction of $\mathrm{HC}$ regeneration (Romero-Carvajal et al., 2015). The Fgf pathway is downregulated after HC loss in neuromasts (Jiang et al., 2014). To get deeper insights into the mechanism of HC regeneration driven by these three important signaling pathways, scRNA-seq showed that $f g f 3$ in zebrafish is only expressed in central SCs under normal conditions and is downregulated when the overlying HCs die (Lush et al., 2019). Moreover, fgf3-null mutant zebrafish neuromast cells showed that the Wnt inhibitor sost was downregulated and the Wnt target gene wnt10a was upregulated, indicating that Wnt signaling is activated in $f g f 3$-null mutants. The authors demonstrated that loss of $f g f 3$ in central SCs led to increased HC regeneration independent of Notch signaling likely through fgfrla and fgfr2 receptors.

\section{REFERENCES}

Adams, M. E., Hurd, E. A., Beyer, L. A., Swiderski, D. L., Raphael, Y., and Martin, D. M. (2007). Defects in vestibular sensory epithelia and innervation in mice with loss of Chd7 function: implications for human CHARGE syndrome. J. Comp. Neurol. 504, 519-532. doi: 10.1002/cne. 21460

Angermueller, C., Clark, S. J., Lee, H. J., Macaulay, I. C., Teng, M. J., Hu, T. X., et al. (2016). Parallel single-cell sequencing links transcriptional

\section{CONCLUSION AND FUTURE DIRECTION}

Over the past decade, SCS technologies have emerged as powerful tools for dissecting cellular heterogeneity and for reconstructing developmental lineages in various tissues, and the application of SCS has brought gene expression studies in inner ear cells to an unprecedented level. SCS provides unbiased research methods for analyzing single cell gene-expression characteristics and global cell heterogeneity in the sensory epithelium, the non-sensory epithelium, and the SGNs, thus allowing the identification of novel marker genes and unknown cell subtypes. AUC ranking and GO analysis point to diverse physiological properties among different cell populations and illustrate the different biological functions of each cell type. The use of SCS in the developing inner ear has revealed dynamic transcriptional profiles, varying signaling pathways, and constantly changing cellular states along the developmental axis, and this has led to the reconstruction of cell lineage progression and the discovery of key regulators of these processes. In addition, SCS supports research into the pathogenic mechanisms of deafness and $\mathrm{HC}$ regeneration. With the help of full-length sequencing, the identification of unannotated exons and isoforms of deafness-related genes has expanded our knowledge of the genetic basis of deafness and provides a foundation for new advances in gene therapy.

Despite the wide application of SCS methods in inner ear research, SCS technologies still require further development to reduce background noise, amplification errors, and costs and to improve coverage and sequencing depth. Single-cell isolation methods also need improvement in order to avoid genetic changes during dissociation. Thus, there is great room for improvement and development in SCS technologies. We anticipate that the future application of single-cell profiling in the inner ear will shed substantial light on the cellular heterogeneity involved in inner ear development and hearing and balance functions and will improve the accuracy of regenerative therapies. The potential of SCS technology remains to be fully explored, and single-cell sequencing technologies are likely to yield new discoveries in inner ear research in the future.

\section{AUTHOR CONTRIBUTIONS}

HL and WL designed this systematic review article and present a synthesis of previous researches on Single-cell sequencing in the inner ear. MW and MX went through all the related manuscript. MW, MX, WL, and HL wrote the manuscript. All the authors contributed to the article and approved the submitted version.

and epigenetic heterogeneity. Nat. Methods 13, 229-232. doi: 10.1038/ nmeth.3728

Arneson, N., Hughes, S., Houlston, R., and Done, S. (2008). Whole-genome amplification by degenerate oligonucleotide primed PCR (DOP-PCR). CSH Protoc. 2008:dbrot4919.

Balak, K. J., Corwin, J. T., and Jones, J. E. (1990). Regenerated Hair-cells can originate from supporting cell progeny - evidence from phototoxicity and laser ablation experiments in the lateral line system. J. Neurosci. 10, 2502-2512. doi: 10.1523/jneurosci.10-08-02502.1990 
Biase, F. H., Cao, X., and Zhong, S. (2014). Cell fate inclination within 2-cell and 4-cell mouse embryos revealed by single-cell RNA sequencing. Genome Res. 24, 1787-1796. doi: 10.1101/gr.177725.114

Bossel Ben-Moshe, N., Hen-Avivi, S., Levitin, N., Yehezkel, D., Oosting, M., Joosten, L. A. B., et al. (2019). Predicting bacterial infection outcomes using single cell RNA-sequencing analysis of human immune cells. Nat. Commun. 10:3266.

Bouazoune, K., and Kingston, R. E. (2012). Chromatin remodeling by the CHD7 protein is impaired by mutations that cause human developmental disorders. Proc. Natl. Acad. Sci. U.S.A. 109, 19238-19243. doi: 10.1073/pnas.1213825109

Buenrostro, J. D., Wu, B., Litzenburger, U. M., Ruff, D., Gonzales, M. L., Snyder, M. P., et al. (2015). Single-cell chromatin accessibility reveals principles of regulatory variation. Nature 523, 486-490. doi: 10.1038/nature14590

Burns, J. C., Kelly, M. C., Hoa, M., Morell, R. J., and Kelley, M. W. (2015). Singlecell RNA-Seq resolves cellular complexity in sensory organs from the neonatal inner ear. Nat. Commun. 6:8557.

Cao, J., Spielmann, M., Qiu, X., Huang, X., Ibrahim, D. M., Hill, A. J., et al. (2019). The single-cell transcriptional landscape of mammalian organogenesis. Nature 566, 496-502. doi: 10.1038/s41586-019-0969-x

Chen, Y., Lu, X. L., Guo, L., Ni, W. L., Zhang, Y. P., Zhao, L. P., et al. (2017). Hedgehog signaling promotes the proliferation and subsequent hair cell formation of progenitor cells in the neonatal mouse cochlea. Front. Mol. Neurosci. 10:426. doi: 10.3389/fnmol.2017.00426

Chen, Y., Zheng, Y., Gao, Y., Lin, Z., Yang, S., Wang, T., et al. (2018). Singlecell RNA-seq uncovers dynamic processes and critical regulators in mouse spermatogenesis. Cell Res. 28, 879-896. doi: 10.1038/s41422-018-0074-y

Cheng, C., Guo, L., Lu, L., Xu, X. C., Zhang, S. S., Gao, J. Y., et al. (2017). Characterization of the transcriptomes of Lgr5+hair cell progenitors and Lgr5supporting cells in the mouse cochlea. Front. Mol. Neurosci. 10:122. doi: 10. 3389/fnmol.2017.00122

Clark, S. J., Argelaguet, R., Kapourani, C. A., Stubbs, T. M., Lee, H. J., AldaCatalinas, C., et al. (2018). scNMT-seq enables joint profiling of chromatin accessibility DNA methylation and transcription in single cells. Nat. Commun. 9:781.

Combe, M., Garijo, R., Geller, R., Cuevas, J. M., and Sanjuan, R. (2015). Singlecell analysis of RNA virus infection identifies multiple genetically diverse viral genomes within single infectious units. Cell Host Microbe 18, 424-432. doi: 10.1016/j.chom.2015.09.009

Corwin, J. T., and Cotanche, D. A. (1988). Regeneration of sensory hair cells after acoustic trauma. Science 240, 1772-1774. doi: 10.1126/science.3381100

Cotanche, D. A., Saunders, J. C., and Tilney, L. G. (1987). Hair cell damage produced by acoustic trauma in the chick cochlea. Hear. Res. 25, 267-286. doi: 10.1016/0378-5955(87)90098-0

Dahlmann, A., and von During, M. (1995). The endolymphatic duct and sac of the rat: a histological, ultrastructural, and immunocytochemical investigation. Cell Tissue Res. 282, 277-289. doi: 10.1007/bf00319118

Dey, S. S., Kester, L., Spanjaard, B., Bienko, M., and Van Oudenaarden, A. (2015). Integrated genome and transcriptome sequencing of the same cell. Nat. Biotechnol. 33, 285-289. doi: 10.1038/nbt.3129

Durruthy-Durruthy, R., Gottlieb, A., Hartman, B. H., Waldhaus, J., Laske, R. D., Altman, R., et al. (2014). Reconstruction of the mouse otocyst and early neuroblast lineage at single-cell resolution. Cell 157, 964-978. doi: 10.1016/j. cell.2014.03.036

Durruthy-Durruthy, R., Sperry, E. D., Bowen, M. E., Attardi, L. D., Heller, S., and Martin, D. M. (2018). Single cell transcriptomics reveal abnormalities in neurosensory patterning of the Chd7 mutant mouse ear. Front. Genet. 9:473. doi: 10.3389/fgene.2018.00473

Ealy, M., Ellwanger, D. C., Kosaric, N., Stapper, A. P., and Heller, S. (2016). Singlecell analysis delineates a trajectory toward the human early otic lineage. Proc. Natl. Acad. Sci. U.S.A. 113, 8508-8513. doi: 10.1073/pnas.1605537113

Ellwanger, D. C., Scheibinger, M., Dumont, R. A., Barr-Gillespie, P. G., and Heller, S. (2018). Transcriptional dynamics of hair-bundle morphogenesis revealed with celltrails. Cell Rep. 23, 2901.e2913-2914.e2913.

Eybalin, M., Norenberg, M. D., and Renard, N. (1996). Glutamine synthetase and glutamate metabolism in the guinea pig cochlea. Hear. Res. 101, 93-101. doi: 10.1016/s0378-5955(96)00136-0

Fan, H. C., Fu, G. K., and Fodor, S. P. A. (2015). Combinatorial labeling of single cells for gene expression cytometry. Science 9:347.
Fasquelle, L., Scott, H. S., Lenoir, M., Wang, J., Rebillard, G., Gaboyard, S., et al. (2011). Tmprss3, a transmembrane serine protease deficient in human DFNB8/10 deafness, is critical for cochlear hair cell survival at the onset of hearing. J. Biol. Chem. 286, 17383-17397. doi: 10.1074/jbc.m110.190652

Fowler, M. R., Colotti, G., Chiancone, E., Smith, G. L., and Fearon, I. M. (2008). Sorcin modulates cardiac L-type Ca2+ current by functional interaction with the alpha1C subunit in rabbits. Exp. Physiol. 93, 1233-1238. doi: 10.1113/ expphysiol.2008.043497

Grant, L., Slapnick, S., Kennedy, H., and Hackney, C. (2006). Ryanodine receptor localisation in the mammalian cochlea: an ultrastructural study. Hear. Res. 219, 101-109. doi: 10.1016/j.heares.2006.06.002

Gross, A., Schoendube, J., Zimmermann, S., Steeb, M., Zengerle, R., and Koltay, P. (2015). Technologies for Single-Cell Isolation. Int. J. Mol. Sci. 16, 16897-16919.

Groves, A. K., and Fekete, D. M. (2012). Shaping sound in space: the regulation of inner ear patterning. Development 139, 245-257. doi: 10.1242/dev.067074

Grun, D., Lyubimova, A., Kester, L., Wiebrands, K., Basak, O., Sasaki, N., et al. (2015). Single-cell messenger RNA sequencing reveals rare intestinal cell types. Nature 525, 251-255. doi: 10.1038/nature14966

Gubbels, S. P., Woessner, D. W., Mitchell, J. C., Ricci, A. J., and Brigande, J. V. (2008). Functional auditory hair cells produced in the mammalian cochlea by in utero gene transfer. Nature 455, 537-541. doi: 10.1038/nature07265

Guo, F., Li, L., Li, J., Wu, X., Hu, B., Zhu, P., et al. (2017a). Single-cell multi-omics sequencing of mouse early embryos and embryonic stem cells. Cell Res. 27, 967-988. doi: 10.1038/cr.2017.82

Guo, F., Li, S., Caglar, M. U., Mao, Z., Liu, W., Woodman, A., et al. (2017b). Singlecell virology: on-chip investigation of viral infection dynamics. Cell Rep. 21, 1692-1704. doi: 10.1016/j.celrep.2017.10.051

Guo, F., Yan, L. Y., Guo, H. S., Li, L., Hu, B. Q., Zhao, Y. Y., et al. (2015). The transcriptome and DNA methylome landscapes of human primordial germ cells. Cell 161, 1437-1452. doi: 10.1016/j.cell.2015.05.015

Guo, H., Zhu, P., Guo, F., Li, X., Wu, X., Fan, X., et al. (2015). Profiling DNA methylome landscapes of mammalian cells with single-cell reducedrepresentation bisulfite sequencing. Nat. Protoc. 10, 645-659. doi: 10.1038/ nprot.2015.039

Guo, J., and Cairns, B. R. (2019). Isolation and enrichment of spermatogonial stem cells from human testis tissues. Curr. Protoc. Stem. Cell Biol. 49:e77. doi: $10.1002 /$ cpsc.77

Guo, R. R., Ma, X. F., Liao, M. H., Liu, Y., Hu, Y. N., Qian, X. Y., et al. (2019). Development and application of cochlear implant-based electricacoustic stimulation of spiral ganglion neurons. ACS Biomater. Sci. Eng. 5, 6735-6741. doi: 10.1021/acsbiomaterials.9b01265

Han, L., Wu, H. J., Zhu, H., Kim, K. Y., Marjani, S. L., Riester, M., et al. (2017). Bisulfite-independent analysis of CpG island methylation enables genome-scale stratification of single cells. Nucleic Acids Res. 45:e77.

Harada, A., Maehara, K., Handa, T., Arimura, Y., Nogami, J., Hayashi-Takanaka, Y., et al. (2019). A chromatin integration labelling method enables epigenomic profiling with lower input. Nat. Cell Biol. 21, 287-296. doi: 10.1038/s41556018-0248-3

Hashimshony, T., Senderovich, N., Avital, G., Klochendler, A., De Leeuw, Y., Anavy, L., et al. (2016). CEL-Seq2: sensitive highly-multiplexed single-cell RNA-Seq. Genome Biol. 17:77.

Hashimshony, T., Wagner, F., Sher, N., and Yanai, I. (2012). CEL-Seq: singlecell RNA-Seq by multiplexed linear amplification. Cell Rep. 2, 666-673. doi: 10.1016/j.celrep.2012.08.003

Hashino, E., Tanaka, Y., and Sokabe, M. (1991). Hair cell damage and recovery following chronic application of kanamycin in the chick cochlea. Hear. Res. 52, 356-368. doi: 10.1016/0378-5955(91)90025-5

He, Y. Z., Lu, X. L., Qian, F. P., Liu, D., Chai, R. J., and Li, H. W. (2017). Insm1a is required for zebrafish posterior lateral line development. Front. Mol. Neurosci. 10:241. doi: 10.3389/fnmol.2017.00241

He, Z. H., Fang, Q. J., Li, H., Shao, B. W., Zhang, Y., Zhang, Y. H., et al. (2019). The role of FOXG1 in the postnatal development and survival of mouse cochlear hair cells. Neuropharmacology 144, 43-57. doi: 10.1016/j.neuropharm.2018.10. 021

He, Z. H., Zou, S. Y., Li, M., Liao, F. L., Wu, X., Sun, H. Y., et al. (2020). The nuclear transcription factor FoxG1 affects the sensitivity of mimetic aging hair cells to inflammation by regulating autophagy pathways. Redox Biol. 28:101364. doi: 10.1016/j.redox.2019.101364 
Hilding, A. C. (1953). The tectorial membrane in the theory of hearing - the significance of the tectorial membrane in the transmission of sound vibrations to the hair cells and a theory of the mechanism of tone location in the cochlea. Acta Oto Laryngol. 43, 490-490.

Hoa, M., Olszewski, R., Li, X., Taukulis, I., Gu, S., Detorres, A., et al. (2020). Characterizing adult cochlear supporting cell transcriptional diversity using single-cell RNA-Seq: validation in the adult mouse and translational implications for the adult human cochlea. Front. Mol. Neurosci. 13:13. doi: $10.3389 /$ fnmol.2020.00013

Honda, K., Kim, S. H., Kelly, M. C., Burns, J. C., Constance, L., Li, X., et al. (2017). Molecular architecture underlying fluid absorption by the developing inner ear. Elife 6:e26851.

Hou, Y., Fan, W., Yan, L., Li, R., Lian, Y., Huang, J., et al. (2013). Genome analyses of single human oocytes. Cell 155, 1492-1506. doi: 10.1016/j.cell.2013.11.040

Hou, Y., Guo, H., Cao, C., Li, X., Hu, B., Zhu, P., et al. (2016). Single-cell triple omics sequencing reveals genetic, epigenetic, and transcriptomic heterogeneity in hepatocellular carcinomas. Cell Res. 26, 304-319. doi: 10.1038/cr.2016.23

Hu, Y., Huang, K., An, Q., Du, G., Hu, G., Xue, J., et al. (2016). Simultaneous profiling of transcriptome and DNA methylome from a single cell. Genome Biol. 17:88.

Huang, L., Ma, F., Chapman, A., Lu, S., and Xie, X. S. (2015). Single-cell wholegenome amplification and sequencing: methodology and applications. Annu. Rev. Genomics Hum. Genet. 16, 79-102.

Ikonomou, L., Herriges, M. J., Lewandowski, S. L., Marsland, R., Villacorta-Martin, C., Caballero, I. S., et al. (2020). The in vivo genetic program of murine primordial lung epithelial progenitors. Nat. Commun. 11:635. doi: 10.1038/ s41467-020-14348-3

Islam, S., Kjallquist, U., Moliner, A., Zajac, P., Fan, J. B., Lonnerberg, P., et al. (2012). Highly multiplexed and strand-specific single-cell RNA 5' end sequencing. Nat. Protoc. 7, 813-828. doi: 10.1038/nprot.2012.022

Jaitin, D. A., Kenigsberg, E., Keren-Shaul, H., Elefant, N., Paul, F., Zaretsky, I., et al. (2014). Massively parallel single-Cell RNA-Seq for marker-free decomposition of tissues into cell types. Science 343, 776-779. doi: 10.1126/science.1247651

Jeng, J. Y., Ceriani, F., Hendry, A., Johnson, S. L., Yen, P., Simmons, D. D., et al. (2020). Hair cell maturation is differentially regulated along the tonotopic axis of the mammalian cochlea. J. Physiol. 598, 151-170. doi: 10.1113/jp279012

Jiang, L., Romero-Carvajal, A., Haug, J. S., Seidel, C. W., and Piotrowski, T. (2014). Gene-expression analysis of hair cell regeneration in the zebrafish lateral line. Proc. Natl. Acad. Sci. U.S.A. 111, E1383-E1392.

Jiang, L., Xu, J., Jin, R., Bai, H., Zhang, M., Yang, S., et al. (2018). Transcriptomic analysis of chicken cochleae after gentamicin damage and the involvement of four signaling pathways (Notch, FGF, Wnt and BMP) in hair cell regeneration. Hear. Res. 361, 66-79. doi: 10.1016/j.heares.2018. 01.004

Kaya-Okur, H. S., Wu, S. J., Codomo, C. A., Pledger, E. S., Bryson, T. D., Henikoff, J. G., et al. (2019). CUT\&Tag for efficient epigenomic profiling of small samples and single cells. Nat. Commun. 10:1930.

Klein, A. M., Mazutis, L., Akartuna, I., Tallapragada, N., Veres, A., Li, V., et al. (2015). Droplet barcoding for single-cell transcriptomics applied to embryonic stem cells. Cell 161, 1187-1201. doi: 10.1016/j.cell.2015.04.044

Knouse, K. A., Wu, J., Whittaker, C. A., and Amon, A. (2014). Single cell sequencing reveals low levels of aneuploidy across mammalian tissues. Proc. Natl. Acad. Sci. U.S.A. 111, 13409-13414. doi: 10.1073/pnas.1415 287111

Korrapati, S., Taukulis, I., Olszewski, R., Pyle, M., Gu, S., Singh, R., et al. (2019). Single cell and single nucleus RNA-Seq reveal cellular heterogeneity and homeostatic regulatory networks in adult mouse stria vascularis. Front. Mol. Neurosci. 12:316. doi: 10.3389/fnmol.2019.00316

Kowalczyk, M. S., Tirosh, I., Heck, D., Rao, T. N., Dixit, A., Haas, B. J., et al. (2015). Single-cell RNA-seq reveals changes in cell cycle and differentiation programs upon aging of hematopoietic stem cells. Genome Res. 25, 1860-1872. doi: $10.1101 /$ gr.192237.115

Ku, W. L., Nakamura, K., Gao, W., Cui, K., Hu, G., Tang, Q., et al. (2019). Singlecell chromatin immunocleavage sequencing ( $\mathrm{scChIC}$-seq) to profile histone modification. Nat. Methods 16, 323-325. doi: 10.1038/s41592-019-0361-7

Lewis, R. M., Hume, C. R., and Stone, J. S. (2012). Atoh1 expression and function during auditory hair cell regeneration in post-hatch chickens. Hear. Res. 289, 74-85. doi: 10.1016/j.heares.2012.04.008
Li, W., Ma, Y., Yu, S., Sun, N., Wang, L., Chen, D., et al. (2017). The mutation-free embryo for in vitro fertilization selected by MALBAC-PGD resulted in a healthy live birth from a family carrying PKD 1 mutation. J. Assist. Reprod. Genet. 34, 1653-1658. doi: 10.1007/s10815-017-1018-Z

Li, W. Y., You, D., Chen, Y., Chai, R. J., and Li, H. W. (2016). Regeneration of hair cells in the mammalian vestibular system. Front. Med. 10:143-151. doi: 10.1007/s11684-016-0451-1

Liberman, M. C. (1982). Single-neuron labeling in the cat auditory nerve. Science 216, 1239-1241. doi: 10.1126/science.7079757

Liu, W. W., Xu, X. C., Fan, Z. M., Sun, G. Y., Han, Y. C., Zhang, D. G., et al. (2019). Wnt signaling activates TP53-induced glycolysis and apoptosis regulator and protects against cisplatin-induced spiral ganglion neuron damage in the mouse cochlea. Antioxid. Redox Signal. 30, 1389-1410. doi: 10.1089/ars.2017.7288

Llorens-Bobadilla, E., Zhao, S., Baser, A., Saiz-Castro, G., Zwadlo, K., and MartinVillalba, A. (2015). Single-cell transcriptomics reveals a population of dormant neural stem cells that become activated upon brain injury. Cell Stem Cell 17, 329-340. doi: 10.1016/j.stem.2015.07.002

Lu, C. C., Appler, J. M., Houseman, E. A., and Goodrich, L. V. (2011). Developmental profiling of spiral ganglion neurons reveals insights into auditory circuit assembly. J. Neurosci. 31, 10903-10918. doi: 10.1523/jneurosci. 2358-11.2011

Lush, M. E., Diaz, D. C., Koenecke, N., Baek, S., Boldt, H., St Peter, M. K., et al. (2019). scRNA-Seq reveals distinct stem cell populations that drive hair cell regeneration after loss of Fgf and Notch signaling. Elife 8:e44431.

Macaulay, I. C., Haerty, W., Kumar, P., Li, Y. I., Hu, T. X., Teng, M. J., et al. (2015). G\&T-seq: parallel sequencing of single-cell genomes and transcriptomes. Nat. Methods 12, 519-522.

Macosko, E. Z., Basu, A., Satija, R., Nemesh, J., Shekhar, K., Goldman, M., et al. (2015). Highly parallel genome-wide expression profiling of individual cells using nanoliter droplets. Cell 161, 1202-1214. doi: 10.1016/j.cell.2015.05.002

McGovern, M. M., Randle, M. R., Cuppini, C. L., Graves, K. A., and Cox, B. C. (2019). Multiple supporting cell subtypes are capable of spontaneous hair cell regeneration in the neonatal mouse cochlea. Development 146:dev171009. doi: 10.1242/dev.171009

McInturff, S., Burns, J. C., and Kelley, M. W. (2018). Characterization of spatial and temporal development of Type I and Type II hair cells in the mouse utricle using new cell-type-specific markers. Biol. Open 7:bio038083. doi: 10.1242/bio. 038083

McLean, J. S., Lombardo, M. J., Badger, J. H., Edlund, A., Novotny, M., YeeGreenbaum, J., et al. (2013). Candidate phylum TM6 genome recovered from a hospital sink biofilm provides genomic insights into this uncultivated phylum. Proc. Natl. Acad. Sci. U.S.A. 110, E2390-E2399.

Morsli, H., Choo, D., Ryan, A., Johnson, R., and Wu, D. K. (1998). Development of the mouse inner ear and origin of its sensory organs. J. Neurosci. 18, 3327-3335. doi: 10.1523/jneurosci.18-09-03327.1998

Navin, N., Kendall, J., Troge, J., Andrews, P., Rodgers, L., Mcindoo, J., et al. (2011). Tumour evolution inferred by single-cell sequencing. Nature 472, 90-94. doi: 10.1038/nature09807

Ni, W. L., Zeng, S., Li, W. Y., Chen, Y., Zhang, S. S., Tang, M. L., et al. (2016). Wnt activation followed by Notch inhibition promotes mitotic hair cell regeneration in the postnatal mouse cochlea. Oncotarget 7, 66754-66768. doi: 10.18632/ oncotarget.11479

Nichterwitz, S., Chen, G., Aguila Benitez, J., Yilmaz, M., Storvall, H., Cao, M., et al. (2016). Laser capture microscopy coupled with Smart-seq2 for precise spatial transcriptomic profiling. Nat. Commun. 7:12139.

Ó Maoiléidigh, D., and Ricci, A. J. (2019). A bundle of mechanisms: inner-ear haircell mechanotransduction. Trends Neurosci. 42, 221-236. doi: 10.1016/j.tins. 2018.12.006

Ono, K., Keller, J., Lopez Ramirez, O., Gonzalez Garrido, A., Zobeiri, O. A., Chang, H. H. V., et al. (2020). Retinoic acid degradation shapes zonal development of vestibular organs and sensitivity to transient linear accelerations. Nat. Commun. 11:63.

Patuzzi, R. (2011). Ion flow in stria vascularis and the production and regulation of cochlear endolymph and the endolymphatic potential. Hear. Res. 277, 4-19. doi: 10.1016/j.heares.2011.01.010

Petitpre, C., Wu, H. H., Sharma, A., Tokarska, A., Fontanet, P., Wang, Y. Q., et al. (2018). Neuronal heterogeneity and stereotyped connectivity in the auditory afferent system. Nat. Commun. 9:3691. 
Pfeiffer, R. R., and Kiang, N. Y. (1965). Spike discharge patterns of spontaneous and continuously stimulated activity in the cochlear nucleus of anesthetized cats. Biophys. J. 5, 301-316. doi: 10.1016/s0006-3495(65)86718-2

Picelli, S., Faridani, O. R., Bjorklund, A. K., Winberg, G., Sagasser, S., and Sandberg, R. (2014). Full-length RNA-seq from single cells using Smart-seq2. Nat. Protoc. 9, 171-181. doi: 10.1038/nprot.2014.006

Pijuan-Sala, B., Griffiths, J. A., Guibentif, C., Hiscock, T. W., Jawaid, W., CaleroNieto, F. J., et al. (2019). A single-cell molecular map of mouse gastrulation and early organogenesis. Nature 566, 490-495. doi: 10.1038/s41586-019-0933-9

Pollen, A. A., Nowakowski, T. J., Shuga, J., Wang, X., Leyrat, A. A., Lui, J. H., et al. (2014). Low-coverage single-cell mRNA sequencing reveals cellular heterogeneity and activated signaling pathways in developing cerebral cortex. Nat. Biotechnol. 32, 1053-1058. doi: 10.1038/nbt.2967

Proserpio, V., and Lonnberg, T. (2016). Single-cell technologies are revolutionizing the approach to rare cells. Immunol. Cell Biol. 94, 225-229. doi: 10.1038/icb. 2015.106

Raft, S., Andrade, L. R., Shao, D., Akiyama, H., Henkemeyer, M., and Wu, D. K. (2014). Ephrin-B2 governs morphogenesis of endolymphatic sac and duct epithelia in the mouse inner ear. Dev. Biol. 390, 51-67. doi: 10.1016/j.ydbio. 2014.02.019

Ramskold, D., Luo, S., Wang, Y. C., Li, R., Deng, Q., Faridani, O. R., et al. (2012). Full-length mRNA-Seq from single-cell levels of RNA and individual circulating tumor cells. Nat. Biotechnol. 30, 777-782. doi: 10.1038/nbt.2282

Ranum, P. T., Goodwin, A. T., Yoshimura, H., Kolbe, D. L., Walls, W. D., Koh, J. Y., et al. (2019). Insights into the Biology of Hearing and Deafness Revealed by Single-Cell RNA Sequencing. Cell Rep. 26, 3160.e3-3171.e3.

Rao, D. A., Arazi, A., Wofsy, D., and Diamond, B. (2020). Design and application of single-cell RNA sequencing to study kidney immune cells in lupus nephritis. Nat. Rev. Nephrol. 16, 238-250. doi: 10.1038/s41581-019-0232-6

Romero-Carvajal, A., Navajas Acedo, J., Jiang, L., Kozlovskaja-Gumbriene, A., Alexander, R., Li, H., et al. (2015). Regeneration of sensory hair cells requires localized interactions between the notch and Wnt pathways. Dev. Cell 34, 267-282. doi: 10.1016/j.devcel.2015.05.025

Sachs, M. B., Young, E. D., and Lewis, R. H. (1974). Discharge patterns of single fibers in the pigeon auditory nerve. Brain Res. 70, 431-447. doi: 10.1016/00068993(74)90253-4

Sasagawa, Y., Danno, H., Takada, H., Ebisawa, M., Tanaka, K., Hayashi, T., et al. (2018). Quartz-Seq2: a high-throughput single-cell RNA-sequencing method that effectively uses limited sequence reads. Genome Biol. 19:29.

Sasagawa, Y., Nikaido, I., Hayashi, T., Danno, H., Uno, K. D., Imai, T., et al. (2013). Quartz-Seq: a highly reproducible and sensitive single-cell RNA sequencing method, reveals non-genetic gene-expression heterogeneity. Genome Biol. $14:$ R31.

Scheffer, D. I., Shen, J., Corey, D. P., and Chen, Z. Y. (2015). Gene expression by mouse inner ear hair cells during development. J. Neurosci. 35, 6366-6380. doi: 10.1523/jneurosci.5126-14.2015

Shapiro, E., Biezuner, T., and Linnarsson, S. (2013). Single-cell sequencing-based technologies will revolutionize whole-organism science. Nat. Rev. Genet. 14, 618-630. doi: 10.1038/nrg3542

Shearer, A. E., Eppsteiner, R. W., Booth, K. T., Ephraim, S. S., Gurrola, J. II, Simpson, A., et al. (2014). Utilizing ethnic-specific differences in minor allele frequency to recategorize reported pathogenic deafness variants. Am. J. Hum. Genet. 95, 445-453. doi: 10.1016/j.ajhg.2014.09.001

Shrestha, B. R., Chia, C., Wu, L., Kujawa, S. G., Liberman, M. C., and Goodrich, L. V. (2018). Sensory neuron diversity in the inner ear is shaped by activity. Cell 174, 1229.e17-1246.e17.

Simmons, D. D., Tong, B., Schrader, A. D., and Hornak, A. J. (2010). Oncomodulin identifies different hair cell types in the mammalian inner ear. J. Comp. Neurol. 518, 3785-3802. doi: 10.1002/cne.22424

Smallwood, S. A., Lee, H. J., Angermueller, C., Krueger, F., Saadeh, H., Peat, J., et al. (2014). Single-cell genome-wide bisulfite sequencing for assessing epigenetic heterogeneity. Nat. Methods 11, 817-820. doi: 10.1038/nmeth.3035

Spits, C., Le Caignec, C., De Rycke, M., Van Haute, L., Van Steirteghem, A., Liebaers, I., et al. (2006). Whole-genome multiple displacement amplification from single cells. Nat. Protoc. 1, 1965-1970. doi: 10.1038/nprot.2006.326

Steiner, A. B., Kim, T., Cabot, V., and Hudspeth, A. J. (2014). Dynamic gene expression by putative hair-cell progenitors during regeneration in the zebrafish lateral line. Proc. Natl. Acad. Sci. U.S.A. 111, E1393-E1401.
Sun, S. H., Babola, T., Pregernig, G., So, K. S., Nguyen, M., Su, S. S. M., et al. (2018). Hair cell mechanotransduction regulates spontaneous activity and spiral ganglion subtype specification in the auditory system. Cell 174, 1247.e151263.e15.

Szarama, K. B., Gavara, N., Petralia, R. S., Kelley, M. W., and Chadwick, R. S. (2012). Cytoskeletal changes in actin and microtubules underlie the developing surface mechanical properties of sensory and supporting cells in the mouse cochlea. Development 139, 2187-2197. doi: 10.1242/dev. 073734

Tang, F., Barbacioru, C., Bao, S., Lee, C., Nordman, E., Wang, X., et al. (2010). Tracing the derivation of embryonic stem cells from the inner cell mass by single-cell RNA-Seq analysis. Cell Stem Cell 6, 468-478. doi: 10.1016/j.stem. 2010.03.015

Tang, F., Barbacioru, C., Wang, Y., Nordman, E., Lee, C., Xu, N., et al. (2009). mRNA-Seq whole-transcriptome analysis of a single cell. Nat. Methods 6, 377-382. doi: 10.1038/nmeth.1315

Tang, P. C., Alex, A. L., Nie, J., Lee, J., Roth, A. A., Booth, K. T., et al. (2019). Defective Tmprss3-associated hair cell degeneration in inner ear organoids. Stem Cell Rep. 13, 147-162. doi: 10.1016/j.stemcr.2019.05.014

Tang, X., Huang, Y., Lei, J., Luo, H., and Zhu, X. (2019). The single-cell sequencing: new developments and medical applications. Cell Biosci. 9:53.

Temchin, A. N. (1988). Unusual discharge patterns of single fibers in the pigeon's auditory nerve. J. Comp. Physiol. A 163, 99-115. doi: 10.1007/bf00612001

Tilney, L. G., and Tilney, M. S. (1988). The actin filament content of hair cells of the bird cochlea is nearly constant even though the length, width, and number of stereocilia vary depending on the hair cell location. J. Cell Biol. 107, 2563-2574. doi: $10.1083 /$ jcb.107.6.2563

Tilney, L. G., Tilney, M. S., and Derosier, D. J. (1992). Actin filaments, stereocilia, and hair cells: how cells count and measure. Annu. Rev. Cell Biol. 8, 257-274. doi: 10.1146/annurev.cb.08.110192.001353

Treutlein, B., Brownfield, D. G., Wu, A. R., Neff, N. F., Mantalas, G. L., Espinoza, F. H., et al. (2014). Reconstructing lineage hierarchies of the distal lung epithelium using single-cell RNA-seq. Nature 509, 371-375. doi: 10.1038/ nature 13173

Wagner, D. E., Weinreb, C., Collins, Z. M., Briggs, J. A., Megason, S. G., and Klein, A. M. (2018). Single-cell mapping of gene expression landscapes and lineage in the zebrafish embryo. Science 360, 981-987. doi: 10.1126/science.aar4362

Wang, M., Liu, X., Chang, G., Chen, Y., An, G., Yan, L., et al. (2018). Single-cell RNA sequencing analysis reveals sequential cell fate transition during human spermatogenesis. Cell Stem Cell 23, 599.e594-614.e594.

Wang, P., Chen, Y. D., Yong, J., Cui, Y. L., Wang, R., Wen, L., et al. (2018). Dissecting the global dynamic molecular profiles of human fetal kidney development by single-Cell RNA sequencing. Cell Rep. 24, 3554.e3-3567.e3.

Wang, T., Chai, R., Kim, G. S., Pham, N., Jansson, L., Nguyen, D. H., et al. (2015). Lgr5+ cells regenerate hair cells via proliferation and direct transdifferentiation in damaged neonatal mouse utricle. Nat. Commun. 6:6613.

Wangemann, P. (2002). K+ cycling and the endocochlear potential. Hear. Res. 165, 1-9. doi: 10.1016/s0378-5955(02)00279-4

Waqas, M., Guo, L., Zhang, S. S., Chen, Y., Zhang, X. L., Wang, L., et al. (2016a). Characterization of Lgr5+progenitor cell transcriptomes in the apical and basal turns of the mouse cochlea. Oncotarget 7, 41123-41141. doi: 10.18632/ oncotarget.8636

Waqas, M., Zhang, S. S., He, Z. H., Tang, M. L., and Chai, R. J. (2016b). Role of Wnt and notch signaling in regulating hair cell regeneration in the cochlea. Front. Med. 10:237-249. doi: 10.1007/s11684-016-0464-9

Wright, M. I. (1973). Ototoxicity: a consideration of routes and mechanisms of hair cell damage associated with certain antibiotics and diuretics. Proc. $R$ Soc. Med. 66, 189-193. doi: 10.1177/003591577306600241

Wu, J. F., Li, W. Y., Lin, C., Chen, Y., Cheng, C., Sun, S., et al. (2016). Coregulation of the Notch and Wnt signaling pathways promotes supporting cell proliferation and hair cell regeneration in mouse utricles. Sci. Rep. 6:29418.

Yamashita, T., Zheng, F., Finkelstein, D., Kellard, Z., Robert, C., Rosencrance, C. D., et al. (2018). High-resolution transcriptional dissection of in vivo Atoh1-mediated hair cell conversion in mature cochleae identifies Isl1 as a coreprogramming factor. PLoS Genet. 14:e1007552. doi: 10.1371/journal.pgen. 1007552

Yan, W. Q., Liu, W. W., Qi, J. Y., Fang, Q. J., Fan, Z. M., Sun, G. Y., et al. (2018). A Three-dimensional culture system with matrigel promotes purified spiral 
ganglion neuron survival and function in vitro. Mol. Neurobiol. 55, 2070-2084. doi: 10.1007/s12035-017-0471-0

Yao, Q., Wang, L., Mittal, R., Yan, D., Richmond, M. T., Denyer, S., et al. (2020). Transcriptomic analyses of inner ear sensory epithelia in Zebrafish. Anat. Rec. 303, 527-543. doi: 10.1002/ar.24331

You, D., Guo, L., Li, W. Y., Sun, S., Chen, Y., Chai, R. J., et al. (2018). Characterization of Wnt and notch-responsive Lgr5+hair cell progenitors in the striolar region of the neonatal mouse utricle. Front. Mol. Neurosci. 11:137. doi: 10.3389/fnmol.2018.00137

Zhang, S., Liu, D., Dong, Y., Zhang, Z., Zhang, Y., Zhou, H., et al. (2019). Frizzled$9+$ supporting cells are progenitors for the generation of hair cells in the postnatal mouse cochlea. Front. Mol. Neurosci. 12:184. doi: 10.3389/fnmol.2019. 00184

Zhang, S. S., Zhang, Y., Yu, P. F., Hu, Y., Zhou, H., Guo, L. N., et al. (2017). Characterization of Lgr5+progenitor cell transcriptomes after neomycin injury in the neonatal mouse cochlea. Front. Mol. Neurosci. 10:213. doi: 10.3389/ fnmol.2017.00213

Zhang, Y. P., Guo, L., Lu, X. L., Cheng, C., Sun, S., Li, W., et al. (2018). Characterization of Lgr6+cells as an enriched population of hair cell progenitors compared to Lgr5+cells for hair cell generation in the neonatal mouse cochlea. Front. Mol. Neurosci. 11:147. doi: 10.3389/fnmol.2018.00147

Zheng, J. L., and Gao, W. Q. (2000). Overexpression of Math1 induces robust production of extra hair cells in postnatal rat inner ears. Nat. Neurosci. 3, 580-586. doi: 10.1038/75753
Zhong, C., Fu, Y., Pan, W., Yu, J., and Wang, J. (2019). Atoh1 and other related key regulators in the development of auditory sensory epithelium in the mammalian inner ear: function and interplay. Dev. Biol. 446, 133-141. doi: 10.1016/j.ydbio.2018.12.025

Zhu, Y., Scheibinger, M., Ellwanger, D. C., Krey, J. F., Choi, D., Kelly, R. T., et al. (2019). Single-cell proteomics reveals changes in expression during hair-cell development. Elife 8:e50777.

Zong, C., Lu, S., Chapman, A. R., and Xie, X. S. (2012). Genome-wide detection of single-nucleotide and copy-number variations of a single human cell. Science 338, 1622-1626. doi: 10.1126/science.1229164

Zwislocki, J. J. (1975). Phase opposition between inner and outer hair cells and auditory sound analysis. Audiology 14, 443-455. doi: 10.3109/ 00206097509071755

Conflict of Interest: The authors declare that the research was conducted in the absence of any commercial or financial relationships that could be construed as a potential conflict of interest.

Copyright (c) $2021 \mathrm{Wu}, \mathrm{Xia}, \mathrm{Li}$ and Li. This is an open-access article distributed under the terms of the Creative Commons Attribution License (CC BY). The use, distribution or reproduction in other forums is permitted, provided the original author(s) and the copyright owner(s) are credited and that the original publication in this journal is cited, in accordance with accepted academic practice. No use, distribution or reproduction is permitted which does not comply with these terms. 